\title{
Microfoundations of Money: Why They Matter
}

\author{
Christopher J. Waller
}

What is the value of having microfoundations for monetary exchange in a macro model? In this article, the author attempts to answer this question by listing what he considers the major accomplishments of the field. He argues that the evidence overwhelmingly shows that microfoundations matter for many questions of first-order importance in macroeconomics. (JEL E41, E47)

Federal Reserve Bank of St. Louis Review, Fourth Quarter 2015, 97(4), pp. 289-301.

$\mathbf{R}$ esearch using search-theoretic models of money is in its third decade and the field is now known as New Monetarist economics. After such a long period, those not working in the field have asked "What major results (those of first-order importance) are obtained from using New Monetarist models that cannot be obtained with a standard cash-in-advance (CIA) model or a cash-credit good (CC) model?" Alternatively, one could rephrase the question as "What is the value of having microfoundations for monetary exchange in a macro model?" In this article, I attempt to answer this question by listing what I consider the major accomplishments of the field. ${ }^{1}$ I argue that the evidence overwhelmingly shows that microfoundations matter for many questions of first-order importance in macroeconomics.

\section{A SHORT HISTORY OF THOUGHT REVIEW}

For centuries economists have understood that money has value because it serves as a medium of exchange. ${ }^{2}$ However, formalizing that result remained elusive. The best that the profession could manage was a simple Wicksellian "triangle" model with a single coincidence of wants. So individual A trades with B, who then trades with $\mathrm{C}$, who then trades with $\mathrm{A}$. The idea is that $\mathrm{A}$ gives $\mathrm{B}$ a unit of money for goods, $\mathrm{B}$ then gives the money to $\mathrm{C}$ for goods, and $\mathrm{C}$ gives the money back to $\mathrm{A}$ for goods. In this model, because there is no double coincidence of wants, money is beneficial for exchange-it is not a hindrance. This is basically how money as a medium of exchange is explained in principles of economics texts.

Christopher J. Waller is senior vice president and director of research at the Federal Reserve Bank of St. Louis. This article draws on presentations given at several conferences. The author thanks Steve Williamson and Ricardo Lagos for comments on an earlier draft of this article.

( ) 2015, Federal Reserve Bank of St. Louis. The views expressed in this article are those of the author(s) and do not necessarily reflect the views of the Federal Reserve System, the Board of Governors, or the regional Federal Reserve Banks. Articles may be reprinted, reproduced, published, distributed, displayed, and transmitted in their entirety if copyright notice, author name(s), and full citation are included. Abstracts, synopses, and other derivative works may be made only with prior written permission of the Federal Reserve Bank of St. Louis. 
Although this concept is very intuitive, it has a peculiar feature-pairwise, decentralized exchange over time. It is now clear why formalizing the medium of exchange role of money was difficult. Since the late 1800s the main analytical framework used by economists to study trade was the Walrasian centralized frictionless market. If that is the main framework for determining prices and the quantities traded, then thinking about the microfoundations of money from the Wicksellian triangular trade model was a dead end. Furthermore, the Wicksellian model involved intertemporal exchange, which required dynamic modelssomething that did not really become a standard part of economists' toolkits until the 1960s and 1970s.

However, one could still think about monetary issues by "forcing" money into an otherwise frictionless economy. Lucas (1980) effectively did this with his CIA model. He took a frictionless dynamic, general equilibrium model and imposed an ad hoc constraint that agents had to use money to pay for consumption goods. This seemed to capture the basic idea that money was used to buy goods. But no attempt was made to understand the deeper frictions that gave rise to this constraint.

The obvious point - that in the real world, people could use cash or credit to buy some consumption goods-led Lucas and Stokey (1987) to develop the CC model of money. In this model, some goods are defined as cash goods, which must be purchased with cash, and some are credit goods, which can be purchased with cash or credit. Although these models captured some basic intuition about the use of money, they nevertheless are reduced-form models of monetary exchange. Furthermore, in both models money is a hindrance to trade since it reduces the set of trades that could be made by arbitrarily ruling out other forms of payment available in the environment.

One could argue that these reduced-form models are sufficient for studying monetary policy and microfoundations are just "details." I have also heard the claim that microfoundations are good because they "justify" using CIA or CC models and once you do this, one can simply assume a CIA or CC model and move on. But there is a fundamental problem with this view: The frictions that give rise to money may create inconsistencies with other parts of the model.

To illustrate this, a CIA constraint actually imposes two restrictions on agents' behavior. First, agents cannot borrow, or have limited borrowing capacity, to finance current purchases of consumption goods. Second, if an agent has more than one asset that can be used for exchange-say, money and equities-then a CIA constraint assumes only money can be used to settle the transaction. It should be obvious that whatever frictions drive the first restriction are generically different from the frictions driving the second restriction. So to support a CIA model, one would need multiple frictions that by some divine coincidence embed both restrictions in a single constraint.

A similar issue arises with the CC model. In CC models, preferences are defined over cash goods and credit goods. (Again, cash goods require cash payment, and credit goods can be purchased with cash or credit). These models appear to be more flexible since they allow agents to borrow to finance purchases of some goods with credit but not others. While this approach sounds appealing, it has two serious problems. 
First, if there are borrowing frictions, then they exist regardless of how payment occurs. One can easily understand that commitment, lack of record-keeping, or asymmetric information problems may give rise to borrowing constraints. However, these problems are often associated with the characteristics of the individuals who are trading. For example, a buyer may have a reputation for defaulting on his debts, so the seller does not issue credit. Or a seller does not have a credit card reader in a store, so he demands cash as payment. But neither example has anything to do with the type of good being exchanged. It thus stretches the imagination to understand why there are differences in commitment or information across the goods that are exchanged. ${ }^{3}$

Second, by defining preferences over cash and credit goods, one has to ask this question: "What is a cash or credit good?" Saying that an orange is a cash good and an apple is a credit good seems strange. Why are oranges and apples being defined by the form of payment? From Debreu we know that goods are defined by their intrinsic nature, time, state, and locationnot by the method of payment. To verify this, ask what the planner solution is-a planner does not care about prices or payment systems. In short, the CC model is a "payment system in the utility function" model.

Rather than forcing money into the economy, some economists began to make headway on understanding the frictions that gave rise to a medium of exchange. A major breakthrough occurred with Wallace's (1980) use, and promotion, of Samuelson's (1958) overlappinggenerations model as a "microfounded" model of money. In that framework, money facilitated trade across time and generations. Although great progress was made over the years using this framework, it had limited appeal to some economists. Money in the overlappinggenerations model is a "long-term" store of value rather than a "high-frequency" medium of exchange. This did not seem to square with the Wicksellian example of decentralized, pairwise trade.

The most important breakthrough in monetary theory came with the work of Kiyotaki and Wright $(1989,1993)$, who used search theory as a foundation for thinking about highfrequency exchange using money. They constructed a dynamic, decentralized trading environment to study pairwise trading. Random matching generated a single coincidence of wants in some matches. Furthermore, with a continuum of agents and a Poisson matching process, the technology of trading meant agent $i$ would never meet agent $j$ again. So promises by $i$ to repay $j$ in the future are not credible; thus, there could be no pairwise credit so all trade had to be quid pro quo. This lack of future interaction is missing in a standard infinitely lived representative agent model with CIA or in a CC model.

Kiyotaki and Wright $(1989,1993)$ studied the endogenous choice to accept an object as a medium of exchange and the fundamentals that drove the acceptance. Reduced-form approaches to money, such as CIA, assume money is always accepted. Thus, an age-old intuition had finally been formalized in a rigorous, dynamic manner where economic fundamentals explained why an intrinsically useless object could have value as a medium of exchange.

The first-generation models of Kiyotaki and Wright $(1989,1993)$ provided interesting "laboratories" to study monetary issues and many interesting results were generated. Yet there was a huge drawback to this generation of models. For tractability, they assumed fixed 
prices due to indivisibility of money and goods. Now, endogenously determining prices is something near and dear to economists' hearts, so just assuming a fixed price was tough to swallow for many. It also precludes thinking about fundamental issues in monetary economics such as the relationship between money growth and inflation. But this work led to the secondgeneration search models of Trejos and Wright (1995) and Shi (1995) that modified Kiyotaki and Wright's framework to study endogenous price determination. But this was tricky since

trade was pairwise. How are the terms of trade determined? Well, it can't be Walrasian pricing! Drawing on the labor search literature, bargaining seemed like a natural way to proceed. So expanding on the first-generation models led monetary economists to consider many new pricing protocols.

However, just as with the first-generation models, the second-generation models had a severe drawback: Money was assumed to be indivisible and agents had inventory constraints on how much money they could hold. Again, the idea that agents could hold only 1 or 2 units of money was again unpalatable to many economists. Progress on this dimension was slowed by a thorny problem: how to deal with the distribution of money balances. Solving for the equilibrium distribution of money balances required either heavy-duty computation (Molico, 2006) or some "trick" that made the distribution of money balances tractable.

Shi (1997) was the first to achieve the latter by incorporating the large household assumption into a search model. Lagos and Wright (2005) introduced a decentralized/centralized trading structure with quasi-linear preferences. Both frameworks effectively control the distribution of money balances so that money becomes degenerate at some point in time. These two models are referred to as third-generation search models that maintain the microfoundations of Kiyotaki and Wright $(1989,1993)$ yet are analytically tractable. As a result, monetary search models were finally ready to be compared head-to-head with CIA models.

\section{KEY FRICTIONS}

A long-standing issue in monetary theory is identifying the key frictions that give rise to money. While many had narrowed down the set, it was Kocherlakota (1998) who laid out the critical frictions for money to be essential. Here "essential" means that introducing money is beneficial and leads to better economic outcomes. He showed that a "gift-giving" (i.e., credit) economy could be supported without using money if the following elements were part of the environment: (i) record-keeping over individual trading histories ("memory"), (ii) public communication of histories, and (iii) sufficient enforcement (or punishment) for transgressions. However, if any of these elements is missing, then money becomes essential to support trade. Consequently, when these elements of the environment are absent, we say that agents are "anonymous."

Note that search and pairwise trade are not contained in Kocherlakota's (1998) list of key elements. So, they are not necessary for money to be essential. Then why continue using search models to study the microfoundations of money? The answer is that search and matching models naturally embed these frictions in their structure of pairwise meetings with single coincidence of wants. 
In the following sections, I outline what I consider five major results of using New Monetarist models that distinguish them from CIA and CC models.

\section{Major Result 1: Endogenous Liquidity Premium}

The first major result is that all search models have an endogenous liquidity premium for the medium of exchange. Let $u(q)$ be the utility of a buyer from expending $q$ units of consumption in an anonymous decentralized match and $-c(q)$ be the disutility of production by a seller in the match. With the third-generation models we can solve for the marginal liquidity premium, which measures the marginal value of an additional unit of money:

$$
\text { Marginal liquidity premium } \equiv L(q)=\sigma\left[\frac{u^{\prime}(q)}{g^{\prime}(q, \theta)}-1\right],
$$

where $\sigma$ is the matching probability, $\theta$ is the buyer's bargaining power, and $g(q, \theta)$ is a function of the bargaining protocol. Buyer-take-all bargaining implies $g^{\prime}(q, 1)=c^{\prime}(q)$. In this case, if $u^{\prime}(q)=c^{\prime}(q)$, trade is efficient and the marginal liquidity premium is zero-in short, money does not carry a liquidity premium because trade is already efficient. However, if $u^{\prime}(q)>c^{\prime}(q)$, then trade is not efficient and a positive liquidity premium arises. The magnitude of this premium depends on the probability of trading, the marginal value of decentralized consumption, and the parameters of the bargaining protocol.

To sharpen the relationship between this marginal liquidity premium and the asset price, suppose that agents in the Lagos-Wright model could trade shares of a Lucas tree in a centralized market and use the shares as a medium of exchange in the anonymous market. If the dividend $d$ is sufficiently low, then the price of a share is given by

$$
p_{t}=\beta E_{t}\left\{\left(p_{t+1}+d_{t}\right)\left[1+L\left(q_{t+1}\right)\right]\right\}
$$

where the asset price is measured in units of the centralized market consumption good. It is clear that when $L\left(q_{t+1}\right)=0$, the marginal liquidity premium is zero and the share trades at its "fundamental" value. However, if $L\left(q_{t+1}\right)>0$, then the price of the share is higher than its fundamental value and its return is lower. The key point of this discussion is that liquidity is a well-defined concept in search models and it can be priced endogenously based on fundamentals of the trading environment.

In equilibrium, agents equate this marginal value of liquidity to the gross return of an interest-bearing asset

$$
1+i=1+\sigma\left[\frac{u^{\prime}(q)}{g^{\prime}(q, \theta)}-1\right]
$$

where $i$ is the one-period nominal interest rate on a riskless bond. It is clear that monetary policy affects the liquidity value of an asset by changing the nominal interest rate; thus, the monetary authority can affect the liquidity premium on assets. 
In the recent financial crisis, people wanted "liquid" assets and this affected asset prices. What is the appropriate policy response in this situation? Standard finance theory should have been able to answer that question but serious answers weren't forthcoming. Why? Well, there really isn't a "theory of liquidity" in standard finance models since they rely on Walrasian markets to determine asset prices—one can always sell an asset at the market price. In short, there is no concept of "illiquidity" in competitive equilibrium. ${ }^{4}$

But from the previous expression it is easy to think about this question. Imagine there is a shock that lowers $\sigma$ (the probability of finding a trading partner falls). This is often how market traders define lower liquidity-when it is harder to find a trading partner. If $i$ is unchanged, then $q$ must fall to maintain the asset price and interest rate on the nominal bond. One can interpret this as a decline in trading volume and greater inefficiency in the exchange. To restore trade in these markets, the monetary authority could lower $i$, which is in fact what the Federal Reserve did in the crisis. Thus, having developed microfoundations for money provides a framework that yields a coherent policy response to a trading shock in the economy.

Using the insight that search and matching frictions affect asset pricing through a liquidity premium, Lagos (2010) used a third-generation model to address the equity premium puzzle and the risk-free rate puzzle. For simplicity, suppose risk-free bonds have a medium of exchange role but stocks do not (or do at a lesser level). Lagos showed that the liquidity premium on bonds is positive and so they demand a higher price, which lowers their return. The lower bond return explains why agents do not hold enough stocks given equity returns (the equity premium puzzle). ${ }^{5}$ The lower return is also less than the time rate of discount, which explains the risk-free rate puzzle. Using a similar insight regarding the role of liquidity in asset pricing, Ravikumar and Shao (2010) show that if $q$ is stochastic, then the asset price volatility will be higher than that implied by the fundamental pricing equation. This also helps to explain the excess volatility puzzle - the fact that the measured volatility of U.S. equity returns is much higher than what is implied by the fundamental asset pricing equation.

Endogenous liquidity premia also allow us to think about hard policy questions such as what to do at the zero lower bound. Once the monetary authority drives the nominal interest rate to the zero lower bound, is there any value from pursuing quantitative easing $(\mathrm{QE})$ ? $\mathrm{QE}$ has no effect at the zero lower bound in a CIA or CC model since the zero lower bound is the best policy the central bank can pursue. Once there, QE has no effect. The same is true in New Keynesian models of the Woodford variety; and, if QE does have real effects, it is because it signals that the central bank will act "irresponsibly" in the future and keep interest rates "too low for too long." On the other hand, as Lagos's (2010) work showed, once you understand that assets have differing liquidity premia that are endogenously determined, new ideas about the effects of QE arise. For example, Williamson (2012) and Boel and Waller (2015) show how QE can still affect inflation and output at the zero lower bound by altering the relative composition of liquid assets in agents' portfolios. This changes the liquidity premia on assets and agents' borrowing constraints. As a result, aggregate economic activity and inflation can be influenced by the monetary authority.

This is why microfoundations matter-they provide new insights for explaining existing puzzles, such as the equity premium puzzle, the excess volatility puzzle, and conducting monetary policy in a liquidity trap. 


\section{Major Result 2: Restricting Liquidity of Some Assets Can Improve Welfare}

Once one contemplates endogenous liquidity premia, then one can begin to understand other asset pricing puzzles. In particular, why do assets that are very close substitutes trade at significantly different prices? For example, a 3-month nominal U.S. Treasury bill pays interest but U.S. currency does not. This seems odd because both are issued by the U.S. government (or a government agency), both have very short holding periods, and Treasury bills pay off in U.S. currency. Since bills earn interest and cash does not, there appears to be a welfare loss from not using T-bills as the medium of exchange. This is exactly the result one would get from using a CIA or CC model-restricting the use of interest-bearing bonds as a payment instrument lowers welfare.

However, as I mentioned earlier, a CIA constraint imposes two frictions-an inability to use credit and the restriction that money is the sole medium of exchange. Once you think of the CIA constraint this way, you must confront the theory of second best-if a friction exists in an economy, then adding (removing) a second friction may improve (worsen) welfare. Now one can ask "Is it possible that restricting the liquidity of some assets can improve welfare?" New Monetarist models show that the answer is yes.

Kocherlakota (2003) was the first to show this. He constructed a model where agents need a liquid asset as a medium of exchange but households experience idiosyncratic shocks to their liquidity needs. He then assumes that households need to choose a portfolio of money and nominal government bonds before their liquidity needs are realized. If money and bonds have identical liquidity properties, then there is no way to reallocate portfolios ex post to alleviate differing needs since assets are identical.

Now if bonds are made illiquid in some manner (legal restrictions), then by the logic above, their liquidity premium falls, the price of the bond falls, and the return increases relative to money. But this will induce those with high liquidity needs to sell bonds for cash, while those with low liquidity needs do the opposite. In short, having illiquid bonds provides for better risk-sharing. Kocherlakota (2003) shows this for a one-time, unexpected liquidity preference shock. So one might believe this result is not a robust one. However, Berentsen and Waller (2011) derive it as a steady-state result. Shi (2008) obtains a similar result but without the need for ex post portfolio adjustment.

Once again, this type of analysis does not occur if one uses a frictionless economy where money is forced into the model as occurs in CIA or CC models. ${ }^{6}$ The key point of this result is that understanding the frictions that drive agents' needs for a liquid asset has implications for understanding other frictions (such as legal restrictions).

\section{Major Result 3: Endogenous Determination of the Medium of Exchange}

In a CIA or CC model, two issues are not addressed-why a medium of exchange is needed and which object should serve that role. Search models provide a foundation for why a medium of exchange is needed (anonymity). Yet when multiple assets are available, even with search models it is difficult to explain which object should serve that role. Why? The curse of "rate of return dominance." Once agents are allowed to trade any of the assets, then 
the object with the best rate of return will be used as the medium of exchange. It is feasible for fiat money to coexist with other media of exchange as long as its rate of return is the same. However, fiat money is almost always dominated in rate of return by other real assets.

Yet we see people use money, not higher-yield assets, as the medium of exchange. So it is a major challenge to explain this without resorting to purely ad hoc restrictions such as CIA. To get at the heart of the issue one has to ask: Is it because sellers will not accept higher-yielding assets as payment? Or is it because buyers will not give up high-yield assets to acquire goods? Basic economics suggests that if the price is sufficiently high, a seller will accept an asset as payment. The reverse also holds for a buyer-if the price is sufficiently low, he will use the high-yield asset to pay for goods. So why does this reasoning fail when it comes to observing real assets serving as media of exchange?

Rocheteau (2011), building on the insights of Williamson and Wright (1994), suggests that asymmetric information is at the heart of the problem. He constructs a model in which real assets have idiosyncratic returns that are either high or low. He then assumes that buyers have inside information about the current return on the real asset they hold. The return on fiat money is common knowledge. This creates a lemons problem: Sellers will accept the real asset only at the lemon (low return) price. Rather than sell a good asset at a bad price, buyers with the high-return real asset retain their asset and choose to pay with money.

Li, Rocheteau, and Weill (2012) extend this idea by assuming that real assets can be counterfeited at a cost. Buyers know whether the assets are genuine but sellers do not. In equilibrium, sellers impose endogenous liquidity constraints on buyers. They will accept a limited amount of the real asset but nothing beyond that. If the buyer desires goods beyond this limit, he must use cash to pay for the additional goods. This limit on the use of real assets as payment makes counterfeiting unattractive. As a result, there is no counterfeiting in equilibrium, and both assets are used as media of exchange even though cash is dominated in rate of return.

Gomis-Porqueras, Kam, and Waller (2015) extend this idea to the case of two fiat currencies by introducing counterfeiting and private information as in Li, Rocheteau, and Weill (2012). A classic result of Kareken and Wallace (1981) is that two currencies can coexist as media of exchange if and only if their rates of return are equal. However, in this case, the nominal exchange rate is indeterminate. Gomis-Porqueras, Kam, and Waller (2015) show that once private information is part of the environment, the nominal exchange rate can be indeterminate or determinate depending on parameter values. If the currencies are identical (the same rate of return and the same counterfeiting costs), the nominal exchange rate can be uniquely determined if the counterfeiting costs are sufficiently large. Otherwise Kareken and Wallace indeterminacy arises. Hence, coexistence and determinacy of the nominal exchange rate are equilibrium outcomes. CIA models eliminate indeterminacy by assumption and do not allow for coexistence as an equilibrium outcome.

Gomis-Porqueras, Peralta-Alva, and Waller (2014) pursue an old idea: that cash allows agents to avoid taxes. They allow for full record-keeping, public communication, and enforcement. Thus, credit can be used in all pairwise matches. But cash is "anonymous," while credit is not (since it requires record-keeping). If credit is used, there is a record of the transaction and it is easier for the government to collect income taxes from the seller. Sellers choose to be 
paid in money to avoid taxes (if inflation is low enough), so they charge a higher price for credit trades. So buyers first use cash to pay for goods and use credit only if they have insufficient cash to buy the desired amount.

None of these papers has restrictions on which asset can be used as payment, yet money can coexist with other higher-yielding assets. Furthermore, these models describe the sequence of which objects are used first to pay for transactions. Endogenous determination of the medium of exchange cannot be done with a CIA or CC model since the choice is assumed from the beginning. The key point of this section is that search models force us to separate (i) borrowing limits from (ii) what is used as the settlement object. In doing so, new results are obtained.

\section{Major Result 4: Big Differences in Optimal Fiscal Policy}

The fourth major result is that search models generate very different predictions for fiscal and monetary policy. For example, in a standard Ramsey analysis of optimal fiscal policy using a CIA or CC model, Chari, Christiano, and Kehoe (1999) show that if preferences are homothetic and separable, then the Friedman rule is optimal and invariant to shocks. Aruoba and Chugh (2010) and Gomis-Porqueras and Peralta-Alva (2010) show this is not true in money search models even if preferences are homothetic and separable. Deviations from the Friedman rule are optimal for very simple and intuitive reasons. In the standard monetary search model, the Friedman rule satisfies $u^{\prime}\left(q^{*}\right)=c^{\prime}\left(q^{*}\right)$. By the envelope theorem small deviations from $q^{*}$ generate second-order welfare losses. With quasi-linear preferences as in Lagos-Wright (2005), a linear labor income tax creates first-order welfare losses. By raising inflation slightly above the Friedman rule, the Ramsey planner generates a second-order welfare loss but can use the seigniorage revenue to reduce labor income taxes, which results in a first-order welfare gain. Consequently, the planner chooses to raise inflation away from the Friedman rule.

Another standard result from the Ramsey taxation literature is that capital should be neither taxed nor subsidized. However, Aruoba, Waller, and Wright (2011) show that in a search-theoretic model with capital accumulation, investment should be subsidized. Why? There is a holdup problem on capital as a result of incomplete contracting. Sellers make ex ante investment decisions regarding the amount of capital used to produce goods in pairwise matches. Random matching and bargaining imply sellers cannot contract ex ante to extract the full surplus from their investment. Thus, capital accumulation is inefficiently low. Optimal fiscal policy should then subsidize capital accumulation to overcome the holdup problem.

Holdup problems are at the center of the modern micro-investment literature (see Caballero, 1999, for a discussion). But it is nearly impossible to get these results in an aggregate macro model because of the assumption of competitive pricing. But as Aruoba, Waller, and Wright (2011) show, holdup problems on investment arise naturally in a search model. The key point is that microfoundations for money generate implications for other parts of the model, such as capital accumulation and taxation, that one simply cannot get using a CIA or CC model. 


\section{Major Result 5: Big Differences in Quantitative Results}

The fifth major result is that search models are quantitatively different from CIA or CC models. Using a CIA model, Cooley and Hansen (1989) show that the welfare cost of 10 percent inflation is 0.5 percent to 1.0 percent of steady-state consumption. Lagos and Wright (2005) find that the welfare cost of 10 percent inflation varies from 1 percent to 7 percent of steady-state consumption, depending on the bargaining power of the buyer. These are serious welfare losses and challenge traditional views about the welfare costs of inflation. Thus, the pricing protocol that arises naturally from pairwise trade has serious quantitative implications for the welfare cost of inflation.

One might think this is not a good comparison since Cooley and Hansen (1989) have capital in their model but Lagos and Wright (2005) do not. But Aruoba, Waller, and Wright (2011) do and they also find very large welfare costs of inflation. They find that the welfare cost of 10 percent inflation ranges from 1 to 3 percent of steady-state consumption. The loss is around 2 percent of steady-state consumption when transition costs are included. They are also able to quantify the welfare cost of the holdup problem on capital, which is estimated to be 3.7 percent of steady-state consumption. Again, this latter estimate could never be obtained using a standard competitive markets model.

Finally, to illustrate another area where microfoundations matter for quantitative estimates, consider the equity premium puzzle mentioned earlier. Lagos (2010) shows that the equity premium puzzle is affected very differently when the assets have endogenous liquidity premia. Mehra and Prescott (2003) calculate the mean equity premium to be 6.92 percent, the return on equities to be 8.07 percent, and the risk-free rate to be 1.15 percent. In their calibrated model with a very high risk aversion parameter of 10, Mehra and Prescott obtain an equity premium of 2.7 percent, which is a bit less than half of the value observed in the data. However, to get this number, the model's imputed return on equity was 15.79 percent and the implied risk-free rate was 13.10 percent. These rates of return are dramatically high compared with the data.

Lagos (2010) shows that, with the same degree of risk aversion, his calibrated search model yields an equity premium of 2.85 percent, which is similar to that of Mehra and Prescott (2003). However, because liquidity premia arise from the two assets, the calibrated return on equities is 4.35 percent and the return on bonds is 1.5 percent; these values are still off but are much closer to the values in the data. Thus, by incorporating the liquidity properties of the assets that arise naturally in a search model, Lagos is able to fit the data much better. The key point of this section is that monetary search models are quantitatively very different from a frictionless economy. In short, monetary frictions are quantitatively important.

\section{SUMMARY}

New Monetarist models incorporate the fundamental frictions that give rise to money. By taking these frictions seriously and formalizing them, the models generate a wide range of new results and issues that are not apparent using standard CIA or CC models. In this article, 
I laid out five major results from the New Monetarist literature that distinguish them from CIA or CC models:

Major result 1: Endogenous liquidity premium

Major result 2: Restricting liquidity of some assets can improve welfare

Major result 3: Endogenous determination of the medium of exchange

Major result 4: Big differences in optimal fiscal policy

Major result 5: Big differences in quantitative results

New Monetarist models have better theoretical foundations than conventional models and generate very different results. So it is puzzling why any monetary economist would continue to use CIA or CC models to study monetary policy when better models are available. 


\section{NOTES}

1 This overview is not intended to be an extensive survey of the literature. The papers mentioned are merely illustrative of a broad body of research on these topics. For exhaustive surveys of the literature, see Williamson and Wright $(2010,2011)$ and Lagos, Rocheteau, and Wright (2015).

2 The following material is related to and draws on arguments made by Wallace (2001).

3 Ricardo Lagos pointed out to me that some goods may be defined this way if one thinks about goods that can be collateralized and seized upon default, such as a house. But this forces one to think about secured versus unsecured lending or durables versus nondurables. In either case, this is not what CC models are trying to capture.

4 It must be noted that the finance literature has moved in the direction of search and matching to study asset pricing, beginning with the work of Duffie, Gârleanu, and Pedersen (2005). But it should be noted that these papers are built on the foundations established by Kiyotaki and Wright $(1989,1993)$.

5 Lagos shows that even if the two assets have the same liquidity properties, this qualitative result holds.

6 This result occurs repeatedly in monetary search models. For example, there are many models that look at welfareimproving deviations from the Friedman rule to overcome another distortion in the economy.

\section{REFERENCES}

Aruoba, S. Borağan and Chugh, Sanjay K. "Optimal Fiscal and Monetary Policy When Money Is Essential." Journal of Economic Theory, September 2010, 145(5), pp. 1618-47.

Aruoba, S. Borağan; Waller, Christopher and Wright, Randall. "Money and Capital." Journal of Monetary Economics, March 2011, 58(2), pp. 98-116.

Berentsen, Aleksander and Waller, Christopher. "Outside Versus Inside Bonds: A Modigliani-Miller Type Result for Liquidity Constrained Households." Journal of Economic Theory, September 2011, 146(5), pp. 1852-87.

Boel, Paola and Waller, Christopher. "On the Theoretical Efficacy of Quantitative Easing at the Zero Lower Bound." Working Paper No. 2015-0271, Federal Reserve Bank of St. Louis, September 2015; https://research.stlouisfed.org/wp/more/2015-027.

Caballero, Ricardo. "Aggregate Investment," in John Taylor and Michael Woodford, eds., Handbook of Macroeconomics. Volume 1B. Amsterdam: Elsevier North Holland, 1999, pp. 813-62.

Chari, V.V.; Christiano, Larry and Kehoe, Patrick. "Optimal Fiscal and Monetary Policy," in John Taylor and Michael Woodford, eds., Handbook of Macroeconomics. Volume 1C. Amsterdam: Elsevier North Holland, 1999, pp. 1672-745.

Cooley, Thomas and Hansen, Gary. "The Inflation Tax in a Real Business Cycle Model." American Economic Review, September 1989, 79(4), pp. 733-48.

Duffie, Darrell; Gârleanu, N. and Pedersen, Lasse H. "Over-the-Counter Markets." Econometrica, November 2005, 73(6), 1815-47.

Gomis-Porqueras, Pedro; Kam, Timothy and Waller, Christopher. "Breaking the Curse of Kareken and Wallace with Private Information." Working Paper No. 2015-028A, Federal Reserve Bank of St. Louis, June 20, 2015; https://research.stlouisfed.org/wp/more/2015-028.

Gomis-Porqueras, Pedro and Peralta-Alva, Adrian. "Optimal Monetary and Fiscal Policies in a Search Theoretic Model of Monetary Exchange." European Economic Review, April 2010, 54(3), pp. 331-44.

Gomis-Porqueras, Pedro; Peralta-Alva, Adrian and Waller, Christopher. "The Shadow Economy as an Equilibrium Outcome." Journal of Economic Dynamics and Control, April 2014, 41, pp. 1-19.

Kareken, John and Wallace, Neil. "On the Indeterminacy of Equilibrium Exchange Rates." Quarterly Journal of Economics, 1981, 96(2), pp. 207-22.

Kiyotaki, Nobuhiro and Wright, Randall. “On Money as a Medium of Exchange." Journal of Political Economy, August 1989, 97(4), pp. 927-54. 
Kiyotaki, Nobuhiro and Wright, Randall. "A Search-Theoretic Approach to Monetary Economics." American Economic Review, March 1993, 83(1), pp. 63-77.

Kocherlakota, Narayana. "Money Is Memory." Journal of Economic Theory, 1998, 81(2), pp. 232-51.

Kocherlakota, Narayana. "Societal Benefits of Illiquid Bonds." Journal of Economic Theory, February 2003, 108(2), pp.179-93.

Lagos, Ricardo. "Asset Prices and Liquidity in an Exchange Economy." Journal of Monetary Economics, November 2010, 57, pp. 913-30.

Lagos, Ricardo and Wright, Randall. "A Unified Framework for Monetary Theory and Policy Evaluation." Journal of Political Economy, 2005, 113(3), pp. 463-84.

Lagos, Ricardo; Rocheteau, Guillaume and Wright, Randall. "Liquidity: A New Monetarist Perspective." 2015, Journal of Economic Literature (forthcoming).

Li, Yiting; Rocheteau, Guillaume and Weill, Pierre-Olivier. "Liquidity and the Threat of Fraudulent Assets." Journal of Political Economy, October 2012, 120(5), pp. 815-46.

Lucas, Robert E. “Equilibrium in a Pure Currency Economy." Economic Inquiry, April 1980, 18(2), pp. 203-20.

Lucas, Robert E. and Stokey, Nancy L. "Money and Interest in a Cash-in-Advance Economy." Econometrica, May 1987, 55(3), pp. 491-513.

Mehra, Rajnish and Prescott, Edward C. "The Equity Premium in Retrospect," in George M. Constantinides, Milton Harris, and Rene M. Stulz, eds., Handbook of the Economics of Finance. Volume 1B. Amsterdam: Elsevier North Holland, 2003, pp. 889-938.

Molico, Miguel. "The Distribution of Money and Prices in Search Equilibrium." International Economic Review, August 2006, 47(3), pp. 701-22.

Ravikumar, B. and Shao, Enchuan. "Search Frictions and Asset Price Volatility." Working Paper No. 2010-1, Bank of Canada, January 2010; http://www.bankofcanada.ca/wp-content/uploads/2010/05/wp10-1.pdf.

Rocheteau, Guillaume. "Payments and Liquidity Under Adverse Selection." Journal of Monetary Economics, April 2011, 58(3), pp. 191-205.

Samuelson, Paul A. "An Exact Consumption-Loan Model of Interest with or without the Social Contrivance of Money." Journal of Political Economy, December 1958, 66(6), pp. 467-82.

Shi, Shouyong. "Money and Prices: A Model of Search and Bargaining." Journal of Economic Theory, December 1995, 67(2), pp. 467-96.

Shi, Shouyong. "A Divisible Search Model of Fiat Money." Econometrica, January 1997, 65(1), pp. 75-102.

Shi, Shouyong. "Efficiency Improvement from Restricting the Liquidity of Nominal Bonds." Journal of Monetary Economics, September 2008, 55(6), pp. 1025-37.

Trejos, Alberto and Wright, Randall. "Search, Bargaining, Money, and Prices." Journal of Political Economy, February 1995, 103(1), pp. 118-41.

Wallace, Neil. "The Overlapping Generations Model of Fiat Money," in Neil Wallace and John Kareken, eds., Models of Monetary Economies. Minneapolis: Federal Reserve Bank of Minneapolis, 1980, pp. 49-82.

Wallace, Neil. "Whither Monetary Economics?" International Economic Review, November 2001, 42(4), pp. 847-69.

Williamson, Stephen D. "Liquidity, Monetary Policy, and the Financial Crisis: A New Monetarist Approach." American Economic Review, October 2012, 102(6), pp. 2570-605.

Williamson, Stephen D. and Wright, Randall. "Barter and Monetary Exchange Under Private Information." American Economic Review, March 1994, 84(1), pp. 104-23.

Williamson, Stephen D. and Wright, Randall. "New Monetarist Economics: Methods." Federal Reserve Bank of St. Louis Review, July/August 2010, 92(4), pp. 265-302; https://research.stlouisfed.org/publications/review/10/07/Williamson.pdf.

Williamson, Stephen D. and Wright, Randall. "New Monetarist Economics: Models," in Benjamin M. Friedman and Michael Woodford, eds., Handbook of Monetary Economics, Volume 3A. Amsterdam: Elsevier North Holland, 2011, pp. 25-96. 
